ఠ

\title{
New developments in the management of opioid dependence: focus on sublingual buprenorphine-naloxone
}

REVIEW

This article was published in the following Dove Press journal:

Substance Abuse and Rehabilitation

6 January 2015

Number of times this article has been viewed

\author{
Michael Soyka ${ }^{1,2}$ \\ 'Department of Psychiatry and \\ Psychotherapy, Ludwig-Maximilians- \\ Universität, Munich, Germany; \\ ${ }^{2}$ Private Hospital Meiringen, \\ Meiringen, Switzerland
}

\begin{abstract}
Opioid maintenance therapy is a well-established first-line treatment approach in opioid dependence. Buprenorphine, a partial opioid agonist, has been found by numerous studies to be an effective and safe medication in the treatment of opioid dependence. At present, buprenorphine is available as a monodrug or in a fixed $4: 1$ ratio combination with naloxone. A diminished risk of diversion and abuse for the buprenorphine-naloxone combination is likely but not firmly established. Conventional formulations are given sublingually to avoid the hepatic first-pass effect. A novel film tablet is available only in the US and Australia. Other novel, sustained-release formulations (implant, depot) are currently being developed and tested. Recent studies, including a Cochrane meta-analysis, suggest that the retention with buprenorphine is lower than for methadone, but that buprenorphine may be associated with less drug use. Higher doses of buprenorphine are associated with better retention rates. Buprenorphine has a ceiling effect at the opioid receptor with regard to respiratory depression, and may cause fewer fatal intoxications than methadone. Possible antidepressant effects of buprenorphine and its use in comorbid psychiatric patients has not been studied in much detail. Clinical implications are discussed.
\end{abstract}

Keywords: buprenorphine, methadone, naloxone, opioids, opioid dependence, therapy

\section{Introduction}

Opioid dependence is a chronic relapsing disorder with a high mortality rate $^{1-5}$ and a high rate of psychiatric and somatic comorbidities. Opioid-use disorders are defined by a problematic pattern of substance use that leads to clinically significant impairment in different areas. According to the International Classification of Diseases tenth revision and the Diagnostic and Statistical Manual of Mental Disorders (DSM)-IV, opioid dependence is a chronic medical disorder defined by a cluster of somatic, psychological, and behavioral symptoms. Both classification systems list eleven symptoms for opioid-use disorders. The recent DSM-5 has given up the long-standing categorical distinction between abuse (or harmful use) and dependence, and adopted a dimensional approach:6,7 it specifies eleven symptoms, whereby the presence of two to three symptoms indicates a mild disorder, four to five a moderate, and six or more a severe disorder.

The nonmedical use of opioids, including heroin, represents a significant public health problem. Epidemiological studies indicate that the worldwide prevalence of opioid-use disorders is about $0.4 \%$ in individuals aged $15-64$ years and that there are 15.5 million opioid-dependent people worldwide, ${ }^{8-10}$ with higher prevalence rates in males and a peak at 25-29 years of age. In Europe, the average prevalence of
Private Hospital Meiringen, PO Box 612, Willigen, Meiringen 3860, Switzerland

Tel +4I 339728295

$\mathrm{Fax}+4 \mathrm{I} 33972829$ I

Email michael.soyka@privatklinik-

meiringen.ch 
problematic opioid use is estimated to be 3.6-4.4 cases per 1,000 population aged $15-64$ years, ${ }^{11}$ corresponding to approximately 1.3 million affected individuals. Recent epidemiological data suggest that prevalence rates for opioid consumption have declined in recent years, at least in Europe, and that there is a shift away from heroin use toward abuse of other opioids, including methadone, buprenorphine (BUP), oxycodone, and fentanyl. ${ }^{12}$

In the US, the 12-month prevalence of drug abuse in general (including opioid use) - with and without dependence - is estimated at 5.7\%, ${ }^{13}$ and current use (past month) at $8.9 \% .{ }^{14}$ Some 3.7 million individuals have used heroin at least once in their lives, and 750,000-1,000,000 individuals are currently heroin-dependent. ${ }^{15}$ The World Health Organization (WHO) estimates that the burden of harm from opioid use is 11.2 million disability-adjusted life-years, ${ }^{16}$ and the recent Global Burden of Disease Study estimates that it is 9.2 million disability-adjusted life-years. ${ }^{10,17}$ In addition, in the US in particular, there is an epidemic of opioid prescription-drug use, and multiple deaths are associated with an overdose of opioid painkillers, including many accidental poisonings in children. ${ }^{18,19}$

Psychotherapy is effective for opioid dependence, but overall abstinence rates remain low. ${ }^{20}$ Opioid-agonist therapy is an established medication and effective not only in reducing opioid consumption and improving psychosocial functioning in opioid addicts ${ }^{21}$ but also in improving psychiatric and somatic health and well-being. ${ }^{21}$ A number of full and partial opioid agonists, including methadone, and such antagonists as naltrexone are now used in the treatment of opioid dependence (see Table 1). BUP, a partial $\mu$-opioid receptor agonist and $\kappa$-antagonist, is one of the most commonly prescribed

Table I Available agents for maintenance treatment of opioid dependence

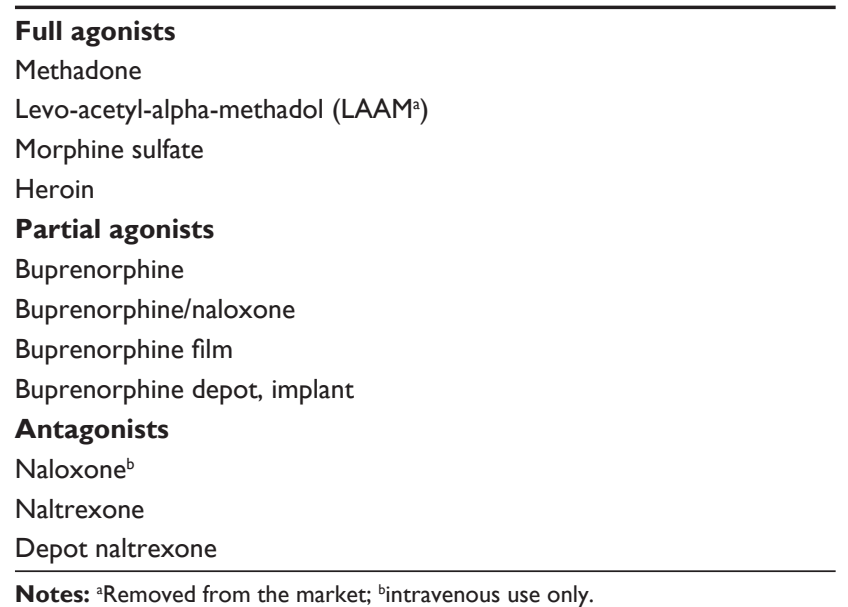

substances, either alone or in combination with naloxone (NLX). This review describes major pharmacological and clinical aspects of BUP, and thereby focuses in particular on efficacy, safety, and psychiatric comorbidity. Novel depot or sustained-release formulations of BUP are not part of this review (for more information on these formulations, see review by Nasser et $\mathrm{al}^{22}$ ).

\section{Buprenorphine in opioid maintenance treatment: overview}

BUP and the BUP/NLX combination are established firstline medications for the treatment of opioid dependence (see American Psychiatric Association [APA] guidelines, ${ }^{15}$ World Federation of Societies of Biological Psychiatry [WFSBP] guidelines, ${ }^{23} \mathrm{New}$ South Wales clinical guidelines, ${ }^{24}$ British Association for Psychopharmacology guidelines, ${ }^{25}$ and WHO guidelines ${ }^{26}$ ); for reviews, see Mammen and Bell, ${ }^{27}$ Orman and Keating, ${ }^{28}$ and Yokell et al. ${ }^{29}$ In the US, BUP was approved by the Food and Drug Administration (FDA) in October 2002 for the treatment of addiction.

\section{Pharmacology}

BUP has a long half-life of 24-60 hours, and is administered sublingually in opioid-replacement therapy. ${ }^{30}$ Bioavailability by the sublingual route was estimated as $51.4 \%$; the terminal elimination half-lives are longer for the sublingual routes than for the intravenous route. ${ }^{31}$ Enterohepatic recirculation of BUP is important, and there is large intersubject and intrasubject variability in plasma concentrations. ${ }^{32}$ Because of extensive first-pass liver metabolism, bioavailability is low after oral administration. Dosages of 4-16 (up to 24-32) $\mathrm{mg}$ /day are usually given for opioid maintenance therapy. Opioid-receptor positron emission tomography data indicate that withdrawal suppression appears to require $50 \%$ or more $\mu$-opioid-receptor availability associated with BUP trough plasma concentrations of at least $1 \mathrm{ng} / \mathrm{mL}$ or more, which in many patients is equivalent to single BUP doses of $4 \mathrm{mg}$. Blockade of the reinforcing and subjective effects of typical doses of abused drugs requires less than $20 \%$ $\mu$-opioid-receptor availability, corresponding to a clinical dose of $16 \mathrm{mg}$ or more. ${ }^{33}$

At present, two tablet forms of BUP are available: one containing only BUP and one that combines BUP with the opioid antagonist NLX in a 4:1 ratio. The novel BUP film tablet is only available in the US and Australia to date. NLX is used as an intravenous medication for the treatment of opioid intoxication, and has very poor oral but good parenteral bioavailability, ${ }^{34,35}$ with an elimination half-life in plasma 
of about 30 minutes to a maximum of 60 minutes. ${ }^{34,36,37}$ The bioavailability of NLX after sublingual administration is too low to cause severe and protracted withdrawal symptoms. ${ }^{37,38}$ NLX does not alter the bioavailability of BUP $16 \mathrm{mg}$ tablets. ${ }^{39}$ When a sublingual dose of BUP/NLX is administered intravenously, however, all opioid addicts experience an immediate opioid-withdrawal syndrome..$^{40-42}$ This effect is thought to reduce the abuse potential of BUP and improve its safety. Hardly any studies in animal models have examined the rewarding or aversive effects of the BUP/NLX combination. ${ }^{43}$ Corresponding to previous findings, ${ }^{44}$ recent experimental data on the abuse potential of intranasal BUP compared to the BUP/NLX combination in BUP-maintained heroin users strongly indicate a reduced abuse potential of the combination drug. ${ }^{45}$

As a partial agonist at the opioid receptor, BUP has a ceiling effect at higher concentrations. ${ }^{30}$ This suggests that when BUP metabolism is inhibited, higher concentrations do not produce typical opioid toxicity effects, such as respiratory depression, and when BUP metabolism is induced, its high affinity for the $\mu$-opioid receptors may allow it to stay on the receptor despite falling plasma concentrations.

\section{Induction of BUP treatment}

Induction of BUP and BUP/NLX in heroin-dependent patients has been found to be safe, ${ }^{46}$ and higher induction doses of BUP have been shown to significantly decrease relapse rates. ${ }^{47}$ BUP may be even safer than methadone in the induction phase. Bell et $\mathrm{al}^{48}$ performed a large datalinkage study and measured mortality in people after initial entry to methadone $(n=2,643)$ and BUP $(n=3,349)$. During induction, the risk of death was lower for BUP. Risk of death was lowest during treatment and significantly higher in the first 12 months after discontinuing either study drug. Twelve months after leaving treatment, risk of death was nonsignificantly higher than during treatment. Additional data gathered over a 9-month period in 13,178 patients on methadone and 2,716 on BUP treatment indicated that BUP had a lower overdose risk than methadone: 60 sudden deaths were positive for methadone (32 in treatment), while seven were positive for BUP (none in treatment) ${ }^{49}$ The induction phase is important in BUP/NLX treatment, and consumption of opioids, cocaine, and benzodiazepines during the first 4 weeks is predictive for further outcome. ${ }^{50}$

Guidelines from the APA, ${ }^{15}$ British Association for Psychopharmacology, ${ }^{25}$ WFSBP, ${ }^{23}$ and others state that BUP is a first-line medication in the treatment of opioid dependence and that the combination tablet significantly reduces the risk of diversion. The BUP/NLX combination may reduce intravenous misuse, but it does not eliminate it (see later). ${ }^{27}$

\section{Clinical efficacy}

BUP effectively suppresses opioid withdrawal. Reduction of opioid use represents the basic outcome criterion in clinical studies of pharmacotherapies in opioid dependence. Other important aspects are the retention rate associated with the use of pharmacotherapies and safety aspects, including risk of diversion.

Previous clinical studies that have compared methadone, primarily in moderate dosages (50-60 mg), with BUP (12-16 mg) have generally demonstrated comparable efficacy of the two drugs. ${ }^{51-56}$ For more detailed background information on the use of BUP in opioid dependence, see Soyka et al. ${ }^{23}$

An important study on treatment retention in patients randomized to $\mathrm{BUP} / \mathrm{NLX}$ or methadone was recently published by Hser et al. ${ }^{57}$ The secondary analysis included 1,267 patients randomized to receive open-label BUP or methadone for 24 weeks. Treatment completion was significantly higher for methadone (74\%) than for BUP (46\%). For BUP, the completion rate increased linearly with higher doses, reaching $60 \%$ at doses of $30-32 \mathrm{mg} /$ day. Of those remaining in treatment, positive opioid urine results were significantly lower among BUP participants than methadone participants during the first 9 weeks of treatment. Higher medication dose was associated with lower opiate use, more so among BUP patients.

Liebschutz et $\mathrm{al}^{58}$ reported results of a randomized clinical trial that included 145 hospitalized opioid-dependent patients who were randomized to either a 5-day BUP detoxification protocol or a linkage program of BUP induction, intrahospital dose stabilization, and postdischarge transition to maintenance BUP treatment and followed up for 6 months. The linkage program was more effective than the inpatientdetoxification protocol.

The recent Cochrane analysis on BUP maintenance for opioid dependence included 31 trials with 5,430 participants. ${ }^{59}$ The group concluded that a high quality of evidence shows that BUP is superior to placebo medication in retention of participants in treatment at all doses examined (2-6 mg, $7-15 \mathrm{mg}$, and $>16 \mathrm{mg}$ ). However, there was moderatequality evidence that only high-dose BUP $(>16 \mathrm{mg})$ was more effective than placebo in suppressing illicit opioid use measured by urine analysis. There also was high-quality evidence that BUP in flexible doses adjusted to participant needs was less effective than methadone in retaining participants. 
For those retained in treatment, no difference was observed in suppression of opioid use. Consistent with the results in the flexible-dose studies, in low fixed-dose studies methadone ( $<40 \mathrm{mg}$ ) was more likely to retain participants. However, contrasting results were found at medium and high doses: medium-dose BUP (7-15 mg) did not differ from mediumdose methadone (40-85 mg) in the retention or suppression of illicit opioid use. Similarly, high-dose BUP $(>16 \mathrm{mg})$ did not differ from high-dose methadone $(>85 \mathrm{mg})$ in retention or heroin use. Only two studies have compared adverse events, and the only finding was more sedation with methadone. BUP is probably less sedative than methadone, although the "clarity" or "clearheadedness" postulated with BUP use is difficult to demonstrate, both clinically and experimentally. The Cochrane analysis does not give much further evidence on this issue. Numerous other studies indicate that higher retention rates are associated with better treatment outcomes in patients in BUP and methadone treatment, eg, Hser et $\mathrm{al}^{57}$ and Gerra et al. ${ }^{6}$ For BUP, psychosocial functioning and addiction severity was found not to be associated with treatment outcome. ${ }^{60}$ Overall, the issue of retention rates remains controversial.

Recent naturalistic data from a large study comparing the effects of methadone and BUP (both formulations) also found a higher retention rate among methadone patients than patients on BUP or BUP/NLX. ${ }^{61}$ With respect to the two BUP formulations, patients in the BUP/NLX group showed a significantly longer average retention than the BUP group. The rates of illicit drug use at 6 months were similar across medication groups.

One possible advantage of BUP is the somewhat easier dose tapering compared to methadone. Although it is difficult to demonstrate the effectiveness of methadone or BUP on the basis of patient profiles, the APA has recommended BUP above other agents for nonsevere physical dependency. ${ }^{15}$ However, the evidence basis for this is weak. ${ }^{23}$ All in all, the drug is a well-established first-line medication for opioid maintenance therapy.

\section{Cognitive function and driving ability in BUP-maintained patients}

In everyday clinical practice, effects on cognitive functions are also of significance. A number of neuropsychological studies, a few of which were prospective and used a randomized control group, have used standardized test batteries to measure domains relevant for psychomotor functioning and driving ability. ${ }^{19,62,63}$ Single doses of BUP have been shown to induce some impairment in healthy volunteers, but less than that found in chronic users. Some nonrandomized studies indicate somewhat better cognitive performance with BUP than methadone, but this finding has not been confirmed in randomized controlled trials. ${ }^{19}$ Most abstinent opiatedependent patients have only mild cognitive impairment or none at all. ${ }^{64}$ Most patients can be judged as fit to drive during maintenance treatment if they are on stable substitution and have no parallel consumption or relevant physical or mental disorders. Most studies indicate at the most only mild-to-moderate cognitive dysfunction in patients treated with BUP under steady-state conditions who have no other concomitant disorders or substance use..$^{19,63}$

\section{Safety profile of BUP}

BUP has a rather favorable safety profile ${ }^{65}$ and a relatively low risk for respiratory depression. ${ }^{66}$ Fatal intoxications are almost always attributable to mixed intoxication with other opioids, benzodiazepines, or alcohol (see later). ${ }^{67}$ BUP side effects are seen in the typical opioid spectrum, and occasionally result in mildly elevated liver enzymes. The possible liver toxicity of BUP, which was raised by some clinical reports of liver injury in patients with hepatitis, has been studied in some detail in recent years. In a retrospective study, Petry et al ${ }^{68}$ found that patients diagnosed with hepatitis $\mathrm{B}$ or $\mathrm{C}$ had significantly increased transaminase levels, while patients without hepatitis did not. Hepatotoxic effects of BUP have been reported in overdose ${ }^{69}$ or intravenous misuse in patients with hepatitis infection. ${ }^{70}$ Some other case reports describe patients with hepatitis $\mathrm{C}$ who developed acute hepatitis while misusing their BUP medication intravenously. ${ }^{71-73}$ Hervé et $\mathrm{al}^{74}$ reported on seven cases of acute cytolytic hepatitis due to BUP. Bruce and Altice ${ }^{75}$ presented a case series of four individuals with acute hepatitis $\mathrm{C}$ infection and abnormal liver transaminases. Patients tolerated BUP treatment well, and their transaminases improved during BUP treatment. Berson et $\mathrm{al}^{73,76}$ proposed a disruption of mitochondrial respiration via proton donation as a possible explanation for the hepatotoxicity of BUP. The issue of possible liver damage by BUP was more systematically studied in a sample of adolescents receiving BUP. ${ }^{77}$ This exploratory study found no evidence for hepatotoxicity of BUP. As part of the submission packet for FDA approval of BUP products, Saxon et $\mathrm{al}^{78}$ conducted a randomized, controlled, 32-week study of opioid-dependent, treatment-seeking patients. A total of 731 participants were randomized to either BUP or methadone. Changes in transaminase levels did not differ by medication, and as expected, baseline infection with hepatitis $\mathrm{C}$ or $\mathrm{B}$ was the only significant predictor for elevation of transaminase lev- 
els. Vergara-Rodriguez et $\mathrm{l}^{79}$ performed an important study on the effects of BUP/NLX on hepatic status in 303 human immunodeficiency virus (HIV)-infected opioid-dependent patients initiating BUP/NLX treatment. BUP/NLX did not produce measurable hepatic toxicity or pharmacodynamic interaction with atazanavir. McNicholas et al ${ }^{80}$ reported data on liver status and enzymes from the National Institute on Drug Abuse-sponsored MOTHER study, a double-blind, double-dummy, flexible-dosing study in 175 pregnant women that compared the effects of methadone and BUP on neonatal outcome. Neither treatment appeared to have adverse hepatic effects. Recently, Lucas et $\mathrm{al}^{81}$ compared liver enzymes during short-term (18 days) and long-term (52 weeks) treatment with BUP/NLX in a large sample of patients $(n=1,036)$. Again, hepatitis $\mathrm{C}$ seroconversion was associated with increased liver values. The risk of hepatotoxicity was similar in opioid injectors receiving brief and those receiving prolonged BUP/ NLX treatment. Finally, recent data from a Phase IV safety study also provided evidence of a low risk of hepatotoxicity in BUP/NLX-maintained patients. ${ }^{82}$

A relative advantage of BUP with regard to cardiac side effects might be that it causes practically no clinically relevant QT prolongation or torsade des pointes, unlike methadone, and subsequently might be used preferentially in patients with cardiac risk factors or QT elongation in their electrocardiogram. ${ }^{83,84}$ Wedam et $\mathrm{al}^{85}$ performed a randomized double-blind clinical trial in 165 patients, and found BUP to be associated with less QTc prolongation than levomethadyl or methadone.

There is broad consensus that the relative advantage of BUP in the substitution treatment of opioid dependency lies in its relative safety and above all in the low risk of lethal overdoses, especially compared with methadone. ${ }^{23}$ There are very few absolute contraindications. ${ }^{86}$ Hardly any cases of respiratory depression have been reported with BUP. ${ }^{66}$ Previous studies, in particular toxicology studies from France, indicate a very low risk of BUP-associated deaths, especially compared to methadone. ${ }^{87,88}$ These findings are supported by a large naturalistic 6-year follow-up study from Germany. To date, only one randomized clinical trial has not found a lower risk of death with BUP than with methadone. ${ }^{90}$

\section{Risk of fatal poisoning/mortality}

A comprehensive review on 58 prospective studies reporting mortality rates from opioid-dependent samples ${ }^{91}$ revealed all-cause mortality rates of 2.09 per 100 person-years, but confirmed that overall maintenance treatment significantly reduces mortality rates compared to untreated heroin dependence. Most patients died from overdose, and risk was higher in male patients and out-of-treatment periods.

The general consensus is that overdoses caused by BUP alone are rare. ${ }^{49,87,92}$ In an epidemiological review, $\mathrm{Okie}^{93}$ concluded that deaths from unintentional drug overdoses in the US have risen sharply since the early 1990s and are the second-leading cause of accidental death (27,658 in 2007). The increase has been propelled by a rising number of overdoses of prescription opioids, which caused more deaths than heroin and cocaine combined in 2007 alone. Other data show that most of the drug-related unintentional deaths in the US are related to methadone (31\%), hydrocodone (19\%), alprazolam (15\%), and oxycodone (15\%). ${ }^{94}$

Few corresponding data are available from European studies. One study found that the numbers of drug-related deaths due to methadone poisoning in Nordic countries has increased from 1991 to $2007,9^{5}$ as did the number of intoxications. BUP was the most frequent cause of death among drug-dependent subjects in Finland $25 \%$ of all intoxications in 2007), while methadone was the most frequent cause of death in Denmark (51\%). Multidrug use was very common in drug-related deaths.

A German naturalistic follow-up study $(n=2,694)$ on 1 -year outcome in opioid-dependent maintenance patients found an overall mortality rate of $1.04 \%$ for methadone- and BUP-treated patients. ${ }^{96}$ The study was a nationally representative prospective longitudinal naturalistic study program with three waves (baseline, 1 year, 5-7 years), and was based on a nationwide representative sample of physicians and their opioid-dependent patients. ${ }^{97}$ During the 6-year follow-up phase, 131 patients had died. Mortality rates were $1.2 \%$ (28 of 2,284) after 1 year and 5.7\% (131 of 2,284) after 6 years, and mean crude annual mortality rates were 1.0 and 1.2 per 100 patient-years, respectively. Mortality rates did not differ between men and women. ${ }^{89}$ The most common causes of death were somatic disorders, drug overdose, and suicide. Fatal overdose of substitution drugs was almost never the sole reason $(1.5 \%)$, and interactions of the substitution drug with other concomitant drugs were relatively rare as well $(6.1 \%)$. In this study, BUP patients had a significantly lower mortality risk (odds ratio $0.27, P=0.005$ ) than methadone patients. At the time of death, $55.7 \%$ patients were no longer in maintenance treatment. Consistent with previous studies, ${ }^{3}$ discontinuation for any reason and being out of treatment were the major predictors for death. This study confirmed such predictors as unemployment, higher age, length of opioid use, and comorbid mental or somatic disorders known from previous studies that addressed shorter follow-up periods. ${ }^{48,91}$ The substantially 
lower rate of premature mortality among BUP-treated patients at the 6-year follow-up was remarkable, ${ }^{89}$ BUP was found to be a significant predictor for survival. These data are consistent with other data from forensic autopsy studies that indicate a low mortality risk with BUP. ${ }^{88}$ Bell et al ${ }^{48}$ reported that BUP may be safer in the induction phase. Degenhardt et $\mathrm{al}^{91}$ estimated the overall reduction in mortality produced by substitution programs to be $29 \%$.

\section{Pharmacokinetic and pharmacodynamic drug interactions with BUP}

Drug interactions with BUP can occur either through altered pharmacokinetics or as a result of pharmacodynamic interactions. ${ }^{98-101}$ Pharmacokinetic interactions can involve the inhibition or induction of hepatic cytochrome P450 (CYP) enzymes and effects on glucuronidation, the function of the drug transporter P-glycoprotein, and drug absorption. ${ }^{98}$ Other mechanisms, such as changes in the permeability of the blood-brain barrier, often are hypothetical. Pharmacodynamic interactions include additive effects of two drugs with similar actions, which in the case of BUP means other central nervous system depressants, such as alcohol or other opioid or psychotropic drugs.

There is general consensus that BUP has fewer possible drug actions than methadone, for both pharmacokinetic and pharmacodynamic reasons. ${ }^{100}$ After sublingual absorption, BUP is primarily converted and $N$-dealkylated to norbuprenorphine, an active metabolite, via CYP3A4 and to a lesser extent by CYP2C8. ${ }^{102-104}$ BUP and norbuprenorphine are further metabolized by uracil diphosphatase glucuronosyltransferases (UGTs), primarily by UGT $1 \mathrm{~A} 3$ and to a lesser extent by 2B6 and 1A1.101,105,106 BUP is not a major inducer or inhibitor of P450 enzymes, but it may compete with other drugs metabolized by these same pathways. BUP is a weak inhibitor of CYP3A4, but this effect does not occur with plasma concentrations achieved at clinically relevant doses. ${ }^{107,108}$ Hydroxylated metabolites of BUP have been identified in vitro and in urine, and their concentrations can be altered by metabolic inhibitors and inducers. ${ }^{104,109,110}$

\section{Pharmacokinetic interactions}

Pharmacokinetic interactions are more complex than pharmacodynamic interactions. There are many possible interactions, but few are clinically meaningful. Most drugs are metabolized in the liver. Of the 40 CYP enzymes in the human body, only six account for $90 \%$ of human drug metabolism: CYP1A2, CYP2C9, CYP2C19, CYP2D6, CYP2E1, and CYP3A4.
CYP3A4 alone metabolizes about $50 \%$ of drugs. Drug-drug interactions with BUP may result in changes in the rate of metabolism of either or both drugs and may subsequently affect plasma drug interactions, among others. ${ }^{98,111}$

CYP3A4 inhibitors may increase plasma BUP concentrations, but the partial agonist effect of BUP may decrease the possibility of overdose and opioid toxicity. Nevertheless, monitoring for side effects, such as sedation or complications (liver toxicity), is recommended and indicated when inhibitors of BUP metabolism are given concomitantly. ${ }^{98,111}$

On the other hand, CYP3A4 inducers may promote enhanced BUP metabolism and subsequently decrease plasma BUP concentrations. Clinically, this may lead to opioid withdrawal, although the ceiling effect and half-life of BUP at the opioid receptor makes this unlikely. ${ }^{98,111}$ In addition, the metabolite norbuprenorphine may be pharmacologically active. ${ }^{112}$ An inhibitory effect of BUP and norbuprenorphine at the CYP2D6 system has been shown in vitro, but is not relevant in humans. ${ }^{107,108,113}$

Moody et $\mathrm{al}^{114}$ pointed out the role of sex differences in the pharmacokinetics of BUP. Women had higher areas under the curve and maximum plasma concentrations for BUP and its metabolites. When corrected for body weight, higher concentrations were only significant for norbuprenorphine. Special conditions, such as pregnancy, ${ }^{99}$ may be associated also with physiological changes and altered drug metabolism. However, this issue is not part of this review. The interested reader is referred to the publications by Gruber and McCanceKatz $^{100}$ and McCance-Katz, ${ }^{98,99}$ for example.

Some specific interactions should be mentioned. Although BUP does not act via the serotonergic system, rare cases of serotonin syndrome have been reported in patients who were also on several antidepressants. ${ }^{115}$ While interactions with anticonvulsants have not been reported, ${ }^{98}$ there are some interactions with antiviral and HIV medications. ${ }^{100}$ Clinically nonsignificant QTc prolongation has been reported for the CYP3A4 inhibitors delavirdine and ritonavir, but not efavirenz or nelfinavir. ${ }^{98}$ Pharmacokinetic and pharmacodynamic interactions of BUP were ruled out for the reverse-transcriptase inhibitors didanosine, lamivudine, tenofovir, ${ }^{116}$ and nevirapine. ${ }^{117}$ Lopinavir/ritonavir does not affect BUP pharmacokinetics but increases clearance of BUP. ${ }^{118}$ While tipranavir/ritonavir does not change BUP levels, decreased plasma levels of the antiviral medication were found. ${ }^{119}$ Interactions between BUP and the protease inhibitors darunavir-ritonavir and fosamprenavir-ritonavir were not detected in a study by Gruber et al. ${ }^{120}$ Significant interactions were ruled out for raltegravir in 
stabilized patients receiving BUP/NLX. ${ }^{121}$ Telaprevir does not interact with BUP metabolism or induce opioid-withdrawal symptoms. ${ }^{122}$ Tramadol interacts via CYP2D6 with methadone but not BUP. ${ }^{123}$ Rifampin is a potent inducer of BUP metabolism, and may produce opioid withdrawal. ${ }^{124}$ In general, drugs that may prolong the QT interval should be used with caution and the patient should be carefully monitored.

Respiratory depression in BUP use has been linked to P-glycoprotein, a drug transporter that plays a key protective role in this respect. In contrast to BUP, the metabolite norbuprenorphine was shown in vitro to be a substrate of human P-glycoprotein. ${ }^{125}$ Drug-drug interactions that lead to P-glycoprotein inhibition may therefore be relevant for BUP-associated fatalities.

\section{Pharmacodynamic interactions}

Pharmacodynamic interactions are likely with other central nervous system depressants, such as alcohol and benzodiazepines. ${ }^{126}$ Interactions with benzodiazepines have been frequently reported, ${ }^{92,127-129}$ although the precise mechanism of increased toxicity is not clear. High-dose diazepam coadministered with BUP was associated with increases in subjective drug effects and decreases in psychological performance. ${ }^{130}$ In an animal model, the combination of BUP and diazepam affected respiratory function. ${ }^{131}$ BUP may also alter desmethylflunitrazepam disposition and flunitrazepam toxicity. ${ }^{132}$ Benzodiazepines, such as clorazepate, may also modify the cell surface of $\mu$-opioid receptors, which may explain the preference of patients for the BUP-benzodiazepine combination. ${ }^{133}$ In vitro studies did not show an inhibition of BUP metabolism in the presence of benzodiazepines. ${ }^{134}$ Clinically, active benzodiazepine (and alcohol) use is an established risk factor for relapse in BUP maintenance. ${ }^{135}$

In the animal model, respiratory effects did not differ between BUP with and without NLX, while in combination with diazepam, BUP increased respiratory depression more than the combination with NLX. ${ }^{131}$

Deaths related to BUP intake nearly exclusively occur in combination with other psychotropic agents or drugs, and fatal monointoxications are rare (see later). Therefore, caution is warranted when psychopharmacotherapy is given to opioid-dependent patients.

\section{Pharmacogenomics}

Recently, genetic variations in the opioid-receptor gene were associated with outcome in BUP treatment, ${ }^{136,137}$ but these findings require further replication.

\section{Recent developments: BUP film tablet}

A BUP/NLX film was developed to address safety issues, improve retention in treatment and bioavailability, and reduce the risk of diversion. Few studies have been published on the efficacy of the novel film tablet, which is currently available only in the US and Australia. ${ }^{19}$ Strain et al ${ }^{138}$ studied the feasibility of induction with a BUP/NLX soluble film in a clinical setting, and performed a randomized study comparing the ability of BUP and BUP/NLX films to suppress spontaneous withdrawal in 34 opioid-dependent volunteers. The authors concluded that BUP and BUP/NLX film tablets are safe and effective delivery methods for opioid induction.

Lintzeris et $\mathrm{al}^{139}$ performed a double-blind, doubledummy, randomized, parallel-group study to compare sublingual BUP/NLX tablets and film with regard to subjective dose effects and equivalence, trough plasma levels, adverse events, patient satisfaction, supervised dosing time, and impact upon treatment outcomes (substance use, psychosocial function) over a 31 -day period $(n=92)$. No significant differences were observed between film and tablets on subjective dose effects, trough plasma BUP, norbuprenorphine levels, adverse events, or treatment outcomes. The BUP/NLX film took significantly less time to dissolve than the tablets. Patient preference appeared to be higher for the film (61\%) than for the tablets $(23 \%)$.

As quoted in Soyka, ${ }^{140}$ an unpublished 12-week, openlabel safety and tolerability study of BUP/NLX film in 194 patients transferred to BUP/NLX film from the tablet (same initial dosage) indicated an overall good tolerability, with $28 \%$ treatment-emergent adverse events, mostly mild in intensity. The most common treatment-emergent adverse event related to the film was oral hypoesthesia (1\%).

The risk of diversion and injection of the novel BUP/NLX film was studied in Australia. ${ }^{141}$ Surveys were conducted with people who inject drugs regularly and opioid-substitution clients $(n=543)$. Among the out-of-treatment patients, levels of injection for BUP/NLX film were comparable with those for methadone and BUP tablet formulations. Among patients in maintenance treatment, rates of recent injecting of medication were similar for all maintenance drugs. Weekly or more frequent injection of prescribed doses was reported by fewer BUP/NLX film patients (3\%) than BUP tablet clients (11\%), but at levels similar to methadone and BUP/NLX tablets. These data question a significant benefit from the use of the novel film compared to conventional BUP/NLX formulations.

The risk of unintentional poisoning in children has been addressed in only a few studies. This issue was studied by 
collecting and examining data from US addiction-related surveillance-system poison centers. Lavonas et $\mathrm{a}^{18}$ reviewed 2,380 cases of unintentional exposures to BUP-containing products among children less than 6 years old, including four deaths (2009-2012). Exposures to BUP/NLX film were significantly less frequent than exposure to BUP tablets (rate ratio 3.5) and BUP/NLX tablets (rate ratio 8.8). These findings correspond with data from a study by the Utah Poison Control Center. ${ }^{142}$

Whether the novel film tablet can increase retention rate with BUP/NLX treatment is a crucial question that has yet to be addressed in head-to-head comparisons with the conventional formulation.

\section{Psychotherapy in BUP- maintained patients}

The issue of psychotherapy during opioid maintenance therapy is rather controversial. Additional psychosocial therapy in opioid maintenance therapy is mandatory in many countries. For patients in methadone maintenance, a Cochrane analysis did not show any clear evidence for beneficial effects of psychosocial therapy. ${ }^{143}$ Some studies indicate that contingency management is effective in this population. ${ }^{144}$ For BUP maintenance, Ling et $\mathrm{al}^{145}$ conducted a randomized study comparing four different behavioral treatment conditions in BUP-maintained patients. Neither cognitive behavioral therapy nor contingency management clearly reduced opioid use when added to BUP and medical management. Similar results were obtained by Fiellin et al. ${ }^{146}$ In this study, among patients receiving BUP/NLX in primary care, the addition of cognitive behavioral therapy did not give extra benefit compared to standard physician management alone. It is probably fair to say that psychosocial therapy in opioid maintenance therapy is important to increase compliance and address the patients' needs, but no gold standard exists for BUP treatment.

\section{BUP in comorbid psychiatric patients}

Overall, mental disorders are common in opiate-dependent people. Their prevalence has been more frequently studied in patients under methadone substitution than in patients receiving BUP/NLX treatment. The studies have shown that the prevalence of depressive syndromes in patients under methadone substitution, especially in those with comorbid cocaine dependence, is at least 25\%-35\%. ${ }^{147-153}$ With regard to BUPsubstituted patients, Savant et al ${ }^{151}$ studied the frequency of affective and substance-induced disorders in 237 consecutively recruited patients under BUP/NLX treatment; 19\% of the patients showed symptoms of a current major depression, and $24 \%$ of the patients reported a history of major depression. Less common were dysthymia $(6 \%)$ and previous mania (1\%) or hypomania (2\%). Furthermore, the rate of additional dependence disorders was relatively high (16\%). Clinically, data from a large German naturalistic 6-year follow-up study of patients in opioid maintenance therapy also indicated a prevalence of depressive disorders of about $42 \%{ }^{67}$

Depressive disorders in opiate-dependent patients often are associated with a higher suicide rate, worse physical health, reduced quality of life, and other symptoms. ${ }^{154-157}$ In addition, the prognosis for opiate-dependent patients with comorbid mental illness is worse than for patients without such a comorbid illness. ${ }^{147,158}$ While depressive disorders otherwise occur mainly in women, this is not the case with opiate dependence. ${ }^{147,150}$

Longitudinal studies have shown that depressive disorders often subside within the first weeks of abstinence treatment. ${ }^{150,159-161}$ Consequently, clinical guidelines recommend waiting for at least 1 week after starting opioidsubstitution treatment before treating a depression. ${ }^{149,152,161,162}$ A number of studies have shown that particularly tricyclic antidepressants are effective in treating depressive symptoms in opiate-dependent patients on substitution therapy, whereby doxepin is slightly more effective than imipramine. ${ }^{23}$

BUP has been evaluated as a possible antidepressant, both in patients with affective disorder and in opiate-dependent patients. A possible pharmacological explanation for an antidepressive effect of BUP is that the substance is not only an opioid agonist at the $\mu$-opioid receptor but also a partial agonist and effective antagonist at the $\kappa$-opioid receptor. The $\kappa$-receptor and its ligand dynorphin appear to play a role in the development of dependence disorders, ${ }^{163}$ as well as in the development of depressive disorders. Kappa antagonists have antidepressive and anxiolytic effects. Various studies have shown that activation of dynorphin is probably associated with depression and anxiety or with negative emotional states. ${ }^{163}$ In the rat model administration of $\kappa$-opioid-receptor agonists can induce depressive conditions. ${ }^{164}$ The combination of opioid $\mu$-agonistic and $\kappa$-antagonistic substances results in less dysphoria than methadone. ${ }^{165}$

Bodkin et $\mathrm{al}^{166}$ evaluated in an open study the efficacy of BUP (0.3-1.8 mg/day) in treatment-resistance unipolar, nonpsychotic major depression. Three of the patients discontinued treatment because of side effects, but after 4-6 weeks the remaining seven patients showed marked improvements in their depressive syndromes. 
Another study found also that BUP is effective in treating depressive illness. ${ }^{167}$ This placebo-controlled, double-blind study investigated ten patients with major depression, and found a pronounced response to BUP in approximately half the patients.

The results of a randomized study in 164 opioid- and cocaine-dependent patients treated with either methadone or BUP and given desipramine found that depressive syndromes were more common in the BUP group at baseline, but not in the further course of the study. Interestingly, in this study desipramine was not more effective than placebo, and in particular the combination with BUP did not appear to have a favorable effect on opiate consumption. The authors discussed whether the "antidepressive" effect of BUP was attributable to differences in the baseline scores for depressive disorders rather than reflecting a therapeutic effect.

Of interest in this context is a retrospective study by Gerra et $\mathrm{al}^{168}$ that evaluated the effects of BUP in dual-diagnosis patients $(\mathrm{n}=206)$. The patients had major depression $(29.6 \%)$, generalized anxiety disorder (11.2\%), personality disorder $(22 \%)$, schizophrenia $(6 \%)$, or a dependence disorder without other mental illnesses (31\%). The main finding of this study was the relevance of depressive disorders: depressed heroindependent patients had a better retention rate and more negative drug urine tests than other so-called dual-diagnosis patients or heroin-dependent patients without psychiatric comorbidity. In an earlier study, Gerra et al had already shown positive treatment results in depressed opiate-dependent patients compared with nondepressed opiate-dependent patients. ${ }^{60}$

Psychotic illnesses are significantly less common in opiate-dependent people under substitution treatment than depression and affective disorders, but they do occur. In the PREMOS study, ${ }^{97,117}$ for example, psychotic disorders were diagnosed in the long-term course in $4.9 \%$ of the patients compared to about $1 \%$ usually found in the general population. Hardly any research has been performed on this topic.

In principle, antipsychotics can be combined with substitution drugs of the BUP type, although possible pharmacological interactions must be considered. Schmauss et al ${ }^{169}$ presumed that BUP would have antipsychotic effects, and consequently studied its effects in ten neuroleptic-free schizophrenia patients with hallucinations and delusions. The 4-day, double-blind, place-controlled, cross-over study (0.2 mg BUP versus placebo) found a pronounced antipsychotic effect of BUP.

Gerra et al ${ }^{170}$ reported the results of a 12 -week prospective observational study in substitution patients who received either olanzapine or haloperidol. Both the rate of negative urine analyses and the retention rate were better with olanzapine. The authors attributed the relative inactivity of "typical" neuroleptics to their "counterproductive" effects on the dopamine reward system in the brain and the induction of extrapyramidal symptoms and dysphoria. In contrast, an analysis of a larger comparative study in Australia of opiate-dependent patients on BUP or methadone found no difference between the groups in the effects on depressive symptoms.

Overall, there is still a considerable need for clinical research on the optimal treatment of comorbid mental illnesses in opiate-dependent patients under substitution treatment. Nevertheless, some findings verify the efficacy of BUP, in particular in depressed opiate-dependent patients.

\section{Discussion and conclusion}

Numerous studies prove the efficacy of BUP and BUP/NLX in maintenance therapy of opioid dependence. Comparisons with methadone are difficult to perform in such a heterogeneous population as opioid-dependent patients, but they appear to indicate that BUP is equally effective in reducing opioid use; the retention rate seems to be somewhat lower with BUP, but the long-term mortality risk may also be lower. Both drugs are first-line medications for the treatment of opioid dependence. Differences in their side-effect profiles and pharmacological interactions may facilitate the choice of drug. Apart from novel formulations, future studies may focus in particular on the effects of BUP on psychiatric aspects or psychiatric comorbidity in opioid-dependent patients.

\section{Acknowledgment}

The author thanks Jacquie Klesing, board-certified editor in the life sciences, for editing assistance with the manuscript.

\section{Disclosure}

The author has worked as a consultant or has received research grants from Sanofi, Cephalopharm, Phoenux, Reckitt Benckiser, and Lundbeck.

\section{References}

1. Bjornaas MA, Bekken AS, Ojlert A, et al. A 20-year prospective study of mortality and causes of death among hospitalized opioid addicts in Oslo. BMC Psychiatry. 2008;8:8.

2. HserYI, Anglin D, Powers K. A 24-year follow-up of California narcotics addicts. Arch Gen Psychiatry. 1993;50:577-584.

3. Peles E, Schreiber S, Adelson M. 15-Year survival and retention of patients in a general hospital-affiliated methadone maintenance treatment (MMT) center in Israel. Drug Alcohol Depend. 2010;107:141-148.

4. Degenhardt L, Bucello C, Calabria B, et al. What data are available on the extent of illicit drug use and dependence globally? Results of four systematic reviews. Drug Alcohol Depend. 2011;117:85-101. 
5. Degenhardt L, Randall D, Hall W, Law M, Butler T, Burns L. Mortality among clients of a state-wide opioid pharmacotherapy program over 20 years: risk factors and lives saved. Drug Alcohol Depend. 2009;105: 9-15.

6. Baumgartner G, Soyka M. [DSM-5 - what has changed in therapy for and research on substance-related and addictive disorders?] Fortschr Neurol Psychiatr. 2013;81:648-654. German.

7. American Psychiatric Association. Diagnostic and Statistical Manual of Mental Disorders. 5th ed. Arlington (VA): American Psychiatric; 2013.

8. Mathers BM, Degenhardt L, Phillips B, et al. Global epidemiology of injecting drug use and HIV among people who inject drugs: a systematic review. Lancet. 2008;372:1733-1745.

9. United Nations Office on Drugs and Crime. 2006 World Drug Report. Vienna: UNODC; 2006

10. Degenhardt L, Whiteford HA, Ferrari AJ, et al. Global burden of disease attributable to illicit drug use and dependence: findings from the Global Burden of Disease Study 2010. Lancet. 2013;382:1564-1574.

11. European Monitoring Centre for Drugs and Drug Addiction. Mortality Related to Drug Use in Europe: Public Health Implications. Lisbon: EMCDDA; 2011.

12. European Monitoring Centre for Drugs and Drug Addiction. European Drug Report 2014. Lisbon: EMCDDA; 2014.

13. Kessler RC, Avenevoli S, Costello EJ, et al. Prevalence, persistence, and sociodemographic correlates of DSM-IV disorders in the National Comorbidity Survey Replication Adolescent Supplement. Arch Gen Psychiatry. 2012;69:372-380.

14. Substance Abuse and Mental Health Services Administration. Results from the 2010 National Survey on Drug Use and Health (NSDUH): Mental Health Findings. Rockville (MD): SHMHSA; 2011.

15. Kleber HD, Weiss RD, Anton RF Jr, et al. Treatment of patients with substance use disorders, second edition. American Psychiatric Association. Am J Psychiatry. 2007;164:5-123.

16. World Health Organization. The World Health Report 2004. Geneva: WHO; 2004.

17. Degenhardt L, Charlson F, Mathers B, et al. The global epidemiology and burden of opioid dependence: results from the global burden of disease 2010 study. Addiction. 2014;109(8):1320-1333.

18. Lavonas EJ, Banner W, Bradt P, et al. Root causes, clinical effects, and outcomes of unintentional exposures to buprenorphine by young children. J Pediatr. 2013;163:1377-1383. e1-e3.

19. Soyka M. Buprenorphine use and risk of abuse and diversion. Adv Pharmacoepidemiol Drug Saf. 2014;3:1-11.

20. Dutra L, Stathopoulou G, Basden SL, Leyro TM, Powers MB, Otto MW. A meta-analytic review of psychosocial interventions for substance use disorders. Am J Psychiatry. 2008;165:179-187.

21. Mattick RP, Breen C, Kimber J, Davoli M. Methadone maintenance therapy versus no opioid replacement therapy for opioid dependence. Cochrane Database Syst Rev. 2009;(3):CD002209.

22. Nasser AF, Heidbreder C, Gomeni R, Fudala PJ, Zheng B, Greenwald MK. A population pharmacokinetic and pharmacodynamic modelling approach to support the clinical development of RBP-6000, a new, subcutaneously injectable, long-acting, sustained-release formulation of buprenorphine, for the treatment of opioid dependence. Clin Pharmacokinet. Epub July 12, 2014.

23. Soyka M, Kranzler HR, van den Brink W, Krystal J, Möller HJ, Kasper S. The World Federation of Societies of Biological Psychiatry (WFSBP) guidelines for the biological treatment of substance use and related disorders. Part 2: Opioid dependence. World J Biol Psychiatry. 2011;12:160-187.

24. New South Wales Department of Health. Opioid Treatment Program: Clinical Guidelines for Methadone and Buprenorphine Treatment. Sydney: NSW Government; 2011.

25. Lingford-Hughes AR, Welch S, Peters L, Nutt DJ. BAP updated guidelines: evidence-based guidelines for the pharmacological management of substance abuse, harmful use, addiction and comorbidity: recommendations from BAP. J Psychopharmacol. 2012;26:899-952.
26. World Health Organization. Guidelines for the Psychosocially Assisted Pharmacological Treatment of Opioid Dependence. Geneva: WHO; 2009.

27. Mammen K, Bell J. The clinical efficacy and abuse potential of combination buprenorphine-naloxone in the treatment of opioid dependence. Expert Opin Pharmacother. 2009;10:2537-2544.

28. Orman JS, Keating GM. Buprenorphine/naloxone: a review of its use in the treatment of opioid dependence. Drugs. 2009;69:577-607.

29. Yokell MA, Zaller ND, Green TC, Rich JD. Buprenorphine and buprenorphine/naloxone diversion, misuse, and illicit use: an international review. Curr Drug Abuse Rev. 2011;4:28-41.

30. Walsh SL, Preston KL, Stitzer ML, Cone EJ, Bigelow GE. Clinical pharmacology of buprenorphine: ceiling effects at high doses. Clin Pharmacol Ther. 1994;55:569-580.

31. Kuhlman JJ Jr, Lalani S, Magluilo J Jr, Levine B, Darwin WD. Human pharmacokinetics of intravenous, sublingual, and buccal buprenorphine. J Anal Toxicol. 1996;20:369-378.

32. Chawarski MC, Moody DE, Pakes J, O’Connor PG, Schottenfeld RS. Buprenorphine tablet versus liquid: a clinical trial comparing plasma levels, efficacy, and symptoms. J Subst Abuse Treat. 2005;29:307-312.

33. Greenwald MK, Comer SD, Fiellin DA. Buprenorphine maintenance and mu-opioid receptor availability in the treatment of opioid use disorder: implications for clinical use and policy. Drug Alcohol Depend. Epub August 19, 2014.

34. Chiang CN, Hawks RL. Pharmacokinetics of the combination tablet of buprenorphine and naloxone. Drug Alcohol Depend. 2003;70: S39-S47.

35. Harris DS, Jones RT, Welm S, Upton RA, Lin E, Mendelson J. Buprenorphine and naloxone co-administration in opiate-dependent patients stabilized on sublingual buprenorphine. Drug Alcohol Depend. 2000;61:85-94.

36. Preston KL, Bigelow GE, Liebson IA. Effects of sublingually given naloxone in opioid-dependent human volunteers. Drug Alcohol Depend. 1990;25:27-34.

37. van Dorp E, Yassen A, Dahan A. Naloxone treatment in opioid addiction: the risks and benefits. Expert Opin Drug Saf. 2007;6:125-132.

38. Preston KL, Bigelow GE, Liebson IA. Effects of sublingually given naloxone in opioid-dependent human volunteers. Drug Alcohol Depend. 1990;25:27-34.

39. Harris DS, Mendelson JE, Lin ET, Upton RA, Jones RT. Pharmacokinetics and subjective effects of sublingual buprenorphine, alone or in combination with naloxone: lack of dose proportionality. Clin Pharmacokinet. 2004:43:329-340.

40. Stoller KB, Bigelow GE, Walsh SL, Strain EC. Effects of buprenorphine/naloxone in opioid-dependent humans. Psychopharmacology (Berl). 2001;154:230-242.

41. Bigelow GE, Preston KL, Liebson IA. Abuse liability assessment of buprenorphine-naloxone combinations. NIDA Res Monogr. 1987;76: $145-149$.

42. Preston KL, Bigelow GE, Liebson IA. Buprenorphine and naloxone alone and in combination in opioid-dependent humans. Psychopharmacology (Berl). 1988;94:484-490.

43. Canestrelli C, Marie N, Noble F. Rewarding or aversive effects of buprenorphine/naloxone combination (Suboxone) depend on conditioning trial duration. Int $J$ Neuropsychopharmacol. 2014;17: 1367-1373.

44. Middleton LS, Nuzzo PA, Lofwall MR, Moody DE, Walsh SL. The pharmacodynamic and pharmacokinetic profile of intranasal crushed buprenorphine and buprenorphine/naloxone tablets in opioid abusers. Addiction. 2011;106:1460-1473.

45. Jones JD, Sullivan MA, Vosburg SK, et al. Abuse potential of intranasal buprenorphine versus buprenorphine/naloxone in buprenorphinemaintained heroin users. Addict Biol. Epub July 25, 2014.

46. Amass L, Pukeleviciene V, Subata E, et al. A prospective, randomized, multicenter acceptability and safety study of direct buprenorphine/ naloxone induction in heroin-dependent individuals. Addiction. 2012;107:142-151. 
47. Leonardi C, Hanna N, Laurenzi P, Fagetti R. Multi-centre observational study of buprenorphine use in 32 Italian drug addiction centres. Drug Alcohol Depend. 2008;94:125-132.

48. Bell J, Trinh L, Butler B, Randall D, Rubin G. Comparing retention in treatment and mortality in people after initial entry to methadone and buprenorphine treatment. Addiction. 2009;104:1193-1200.

49. Bell JR, Butler B, Lawrance A, Batey R, Salmelainen P. Comparing overdose mortality associated with methadone and buprenorphine treatment. Drug Alcohol Depend. 2009;104:73-77.

50. Apelt SM, Scherbaum N, Soyka M. Induction and switch to buprenorphine-naloxone in opioid dependence treatment: Predictive value of the first four weeks. Heroin Addict Relat Clin Probl. 2014;16.

51. Kakko J, Grönbladh L, Svanborg KD, et al. A stepped care strategy using buprenorphine and methadone versus conventional methadone maintenance in heroin dependence: a randomized controlled trial. Am J Psychiatry. 2007;164:797-803.

52. Kamien JB, Branstetter SA, Amass L. Buprenorphine-naloxone versus methadone maintenance therapy: a randomised double-blind trial with opioid-dependent patients. Heroin Addict Relat Clin Probl. 2008;10: $5-18$.

53. Ling W, Jacobs P, Hillhouse M, et al. From research to the real world: buprenorphine in the decade of the Clinical Trials Network. J Subst Abuse Treat. 2010;38 Suppl 1:S53-S60.

54. Schottenfeld RS, Pakes JR, Oliveto A, Ziedonis D, Kosten TR. Buprenorphine vs methadone maintenance treatment for concurrent opioid dependence and cocaine abuse. Arch Gen Psychiatry. 1997;54: 713-720.

55. Soyka M, Zingg C, Koller G, Kuefner H. Retention rate and substance use in methadone and buprenorphine maintenance therapy and predictors of outcome: results from a randomized study. Int $J$ Neuropsychopharmacol. 2008;11:641-653.

56. Ling W, Wesson DR, Charuvastra C, Klett CJ. A controlled trial comparing buprenorphine and methadone maintenance in opioid dependence. Arch Gen Psychiatry. 1996;53:401-407.

57. Hser YI, Saxon AJ, Huang D, et al. Treatment retention among patients randomized to buprenorphine/naloxone compared to methadone in a multi-site trial. Addiction. 2014;109:79-87.

58. Liebschutz JM, Crooks D, Herman D, et al. Buprenorphine treatment for hospitalized, opioid-dependent patients: a randomized clinical trial. JAMA Intern Med. 2014;174:1369-1376.

59. Mattick RP, Breen C, Kimber J, Davoli M. Buprenorphine maintenance versus placebo or methadone maintenance for opioid dependence. Cochrane Database Syst Rev. 2014;2:CD002207.

60. Gerra G, Borella F, Zaimovic A, et al. Buprenorphine versus methadone for opioid dependence: predictor variables for treatment outcome. Drug Alcohol Depend. 2004;75:37-45.

61. Proctor SL, Copeland AL, Kopak AM, Herschman PL, Polukhina N. A naturalistic comparison of the effectiveness of methadone and two sublingual formulations of buprenorphine on maintenance treatment outcomes: findings from a retrospective multisite study. Exp Clin Psychopharmacol. 2014;22(5):424-433.

62. Mintzer MZ. Effects of opioid pharmacotherapy on psychomotor and cognitive performance: a review of human laboratory studies of methadone and buprenorphine. Heroin Addict Relat Clin Prob. 2007;9 5-24.

63. Strand MC, Fjeld B, Arnestad M, Mørland J. Can patients receiving opioid maintenance therapy safely drive? A systematic review of epidemiological and experimental studies on driving ability with a focus on concomitant methadone or buprenorphine administration. Traffic Inj Prev. 2013;14:26-38.

64. Mintzer MZ, Copersino ML, Stitzer ML. Opioid abuse and cognitive performance. Drug Alcohol Depend. 2005;78:225-230.

65. Apelt SM, Scherbaum N, Gölz J, Backmund M, Soyka M. Safety, effectiveness and tolerance of buprenorphine-naloxone in the treatment of opioid dependence: results from a nationwide noninterventional study in routine care. Pharmacopsychiatry. 2013;46: 94-107.
66. Davids E, Gastpar M. Buprenorphine in the treatment of opioid dependence. Eur Neuropsychopharmacol. 2004;14:209-216.

67. Wittchen HU, Boehringer G, Rehm JT, et al. [The course and outcome after 6 years of substitution patients under current conditions of substitution care in Germany]. Suchtmed. 2011;13:232-246. German.

68. Petry NM, Bickel WK, Piasecki D, Marsch LA, Badger GJ. Elevated liver enzyme levels in opioid-dependent patients with hepatitis treated with buprenorphine. Am J Addict. 2000;9:265-269.

69. Houdret N, Asnar V, Szostak-Talbodec N, et al. [Hepatonephritis and massive ingestion of buprenorphine]. Acta Clin Belg Suppl. 1999;1: 29-31. French.

70. Peyrière H, Tatem L, Bories C, Pageaux GP, Blayac JP, Larrey D. Hepatitis after intravenous injection of sublingual buprenorphine in acute hepatitis C carriers: report of two cases of disappearance of viral replication after acute hepatitis. Ann Pharmacother. 2009;43:973-977.

71. Abboud G, Kaplowitz N. Drug-induced liver injury. Drug Saf. 2007;30: 277-294.

72. Aithal GP, Watkins PB, Andrade RJ, et al. Case definition and phenotype standardization in drug-induced liver injury. Clin Pharmacol Ther. 2011;89:806-815

73. Berson A, Gervais A, Cazals D, et al. Hepatitis after intravenous buprenorphine misuse in heroin addicts. J Hepatol. 2001;34:346-350.

74. Hervé S, Riachi G, Noblet C, et al. Acute hepatitis due to buprenorphine administration. Eur J Gastroenterol Hepatol. 2004;16:1033-1037.

75. Bruce RD, Altice FL. Case series on the safe use of buprenorphine/naloxone in individuals with acute hepatitis $\mathrm{C}$ infection and abnormal hepatic liver transaminases. Am J Drug Alcohol Abuse. 2007;33:869-874.

76. Berson A, Fau D, Fornacciari R, et al. Mechanisms for experimental buprenorphine hepatotoxicity: major role of mitochondrial dysfunction versus metabolic activation. J Hepatol. 2001;34:261-269.

77. Bogenschutz MP, Abbott PJ, Kushner R, Tonigan JS, Woody GE. Effects of buprenorphine and hepatitis $\mathrm{C}$ on liver enzymes in adolescents and young adults. J Addict Med. 2010;4:211-216.

78. Saxon AJ, Ling W, Hillhouse M, et al. Buprenorphine/naloxone and methadone effects on laboratory indices of liver health: a randomized trial. Drug Alcohol Depend. 2013;128:71-76.

79. Vergara-Rodriguez P, Tozzi MJ, Botsko M, et al. Hepatic safety and lack of antiretroviral interactions with buprenorphine/naloxone in HIVinfected opioid-dependent patients. J Acquir Immune Defic Syndr. 2011; 56 Suppl 1:S62-S67.

80. McNicholas LF, Holbrook AM, O'Grady KE, et al. Effect of hepatitis C virus status on liver enzymes in opioid-dependent pregnant women maintained on opioid-agonist medication. Addiction. 2012;107 Suppl 1: 91-97.

81. Lucas GM, Young A, Donnell D, et al. Hepatotoxicity in a 52-week randomized trial of short-term versus long-term treatment with buprenorphine/naloxone in HIV-negative injection opioid users in China and Thailand. Drug Alcohol Depend. 2014;142:139-145.

82. Soyka M, Backmund M, Schmidt P, Apelt SM. Buprenorphinenaloxone treatment in opioid dependence and risk of liver enzyme elevation - results from a 12-month observational study. Am J Addict. 2014;23:563-569.

83. Hanon S, Seewald RM, Yang F, Schweitzer P, Rosman J. Ventricular arrhythmias in patients treated with methadone for opioid dependence. J Interv Card Electrophysiol. 2010;28:19-22.

84. Krantz MJ, Garcia JA, Mehler PS. Effects of buprenorphine on cardiac repolarization in a patient with methadone-related torsade de pointes. Pharmacotherapy. 2005;25:611-614.

85. Wedam EF, Bigelow GE, Johnson RE, Nuzzo PA, Haigney MC. QT-interval effects of methadone, levomethadyl, and buprenorphine in a randomized trial. Arch Intern Med. 2007;167:2469-2475.

86. Kraus ML, Alford DP, Kotz MM, et al. Statement of the American Society Of Addiction Medicine Consensus Panel on the use of buprenorphine in office-based treatment of opioid addiction. J Addict Med. 2011;5:254-263.

87. Auriacombe M, Franques P, Tignol J. Deaths attributable to methadone vs buprenorphine in France. JAMA. 2001;285:45. 
88. Pirnay S, Borron SW, Giudicelli CP, Tourneau J, Baud FJ, Ricordel I. A critical review of the causes of death among post-mortem toxicological investigations: analysis of 34 buprenorphine-associated and 35 methadone-associated deaths. Addiction. 2004;99:978-988.

89. Soyka M, Träder A, Klotsche J, et al. Six-year mortality rates of patients in methadone and buprenorphine maintenance therapy: results from a nationally representative cohort study. J Clin Psychopharmacol. 2011;31:678-680.

90. Gibson A, Degenhardt L, Mattick RP, Ali R, White J, O’Brien S. Exposure to opioid maintenance treatment reduces long-term mortality. Addiction. 2008;103:462-468.

91. Degenhardt L, Bucello C, Mathers B, et al. Mortality among regular or dependent users of heroin and other opioids: a systematic review and meta-analysis of cohort studies. Addiction. 2011;106:32-51.

92. Kintz P. Deaths involving buprenorphine: a compendium of French cases. Forensic Sci Int. 2001;121:65-69.

93. Okie S. A flood of opioids, a rising tide of deaths. $N$ Engl J Med. 2010;363:1981-1985.

94. Piercefield E, Archer P, Kemp P, Mallonee S. Increase in unintentional medication overdose deaths: Oklahoma, 1994-2006. Am J Prev Med. 2010;39:357-363.

95. Simonsen KW, Normann PT, Ceder G, et al. Fatal poisoning in drug addicts in the Nordic countries in 2007. Forensic Sci Int. 2011;207: $170-176$

96. Soyka M, Apelt SM, Lieb M, Wittchen HU. One-year mortality rates of patients receiving methadone and buprenorphine maintenance therapy: a nationally representative cohort study in 2694 patients. J Clin Psychopharmacol. 2006;26:657-660.

97. Wittchen HU, Apelt SM, Soyka M, et al. Feasibility and outcome of substitution treatment of heroin-dependent patients in specialized substitution centers and primary care facilities in Germany: a naturalistic study in 2694 patients. Drug Alcohol Depend. 2008;95:245-257.

98. McCance-Katz E. Drug-Drug Interactions in Opioid Therapy. 7th ed. London: PCM Healthcare; 2012.

99. McCance-Katz EF. Drug interactions associated with methadone, buprenorphine, cocaine, and HIV medications: implications for pregnant women. Life Sci. 2011;88:953-958.

100. Gruber VA, McCance-Katz EF. Methadone, buprenorphine, and street drug interactions with antiretroviral medications. Curr HIV/AIDS Rep. 2010;7:152-160.

101. Saber-Tehrani AS, Bruce RD, Altice FL. Pharmacokinetic drug interactions and adverse consequences between psychotropic medications and pharmacotherapy for the treatment of opioid dependence. Am J Drug Alcohol Abuse. 2011;37:1-11.

102. Kobayashi K, Yamamoto T, Chiba T, et al. Human buprenorphine N-dealkylation is catalyzed by cytochrome P450 3A4. Drug Metab Dispos. 1988;26:818-821.

103. Moody DE, Slawson MH, Strain EC, Laycock JD, Spanbauer AC, Foltz RL. A liquid chromatographic-electrospray ionization-tandem mass spectrometric method for determination of buprenorphine, its metabolite, norbuprenorphine, and a coformulant, naloxone, that is suitable for in vivo and in vitro metabolism studies. Anal Biochem. 2002;306:31-39.

104. Picard N, Cresteil T, Djebli N, Marquet P. In vitro metabolism study of buprenorphine: evidence for new metabolic pathways. Drug Metab Dispos. 2005;33:689-695.

105. Chang Y, Moody DE. Glucuronidation of buprenorphine and norbuprenorphine by human liver microsomes and UDPglucuronosyltransferases. Drug Metab Lett. 2009;3:101-107.

106. Rouguieg K, Picard N, Sauvage FL, Gaulier JM, Marquet P. Contribution of the different UDP-glucuronosyltransferase (UGT) isoforms to buprenorphine and norbuprenorphine metabolism and relationship with the main UGT polymorphisms in a bank of human liver microsomes. Drug Metab Dispos. 2010;38:40-45.

107. Umehara K, Shimokawa Y, Miyamoto G. Inhibition of human drug metabolizing cytochrome P450 by buprenorphine. Biol Pharm Bull. 2002;25:682-685.
108. Zhang W, Ramamoorthy Y, Tyndale RF, Sellers EM. Interaction of buprenorphine and its metabolite norbuprenorphine with cytochromes p450 in vitro. Drug Metab Dispos. 2003;31:768-772.

109. Moody DE, Chang Y, Huang W, McCance-Katz EF. The in vivo response of novel buprenorphine metabolites, M1 and M3, to antiretroviral inducers and inhibitors of buprenorphine metabolism. Basic Clin Pharmacol Toxicol. 2009;105:211-215.

110. Chang Y, Moody DE, McCance-Katz EF. Novel metabolites of buprenorphine detected in human liver microsomes and human urine. Drug Metab Dispos. 2006;34:440-448.

111. Gründer G, Benkert O. Handbuch der Psychopharmakotherapie [Handbook of Psychopharmacotherapy]. 2nd ed. Berlin Heidelberg: Springer; 2012.

112. Moody DE. Metabolic and toxicological considerations of the opioid replacement therapy and analgesic drugs: methadone and buprenorphine. Expert Opin Drug Metab Toxicol. 2013;9:675-697.

113. Umeda S, Harakawa N, Yamamoto M, Ueno K. Effect of nonspecific binding to microsomes and metabolic elimination of buprenorphine on the inhibition of cytochrome P4502D6. Biol Pharm Bull. 2005;28: 212-216.

114. Moody DE, Fang WB, Morrison J, McCance-Katz E. Gender differences in pharmacokinetics of maintenance dosed buprenorphine. Drug Alcohol Depend. 2011;118:479-483.

115. Isenberg D, Wong SC, Curtis JA. Serotonin syndrome triggered by a single dose of suboxone. Am J Emerg Med. 2008;26:840 e3-5.

116. Baker J, Rainey PM, Moody DE, Morse GD, Ma Q, McCance-Katz EF. Interactions between buprenorphine and antiretrovirals: nucleos(t)ide reverse transcriptase inhibitors (NRTI) didanosine, lamivudine, and tenofovir. Am J Addict. 2010;19:17-29.

117. McCance-Katz EF, Moody DE, Morse GD, Ma Q, Rainey PM. Lack of clinically significant drug interactions between nevirapine and buprenorphine. Am J Addict. 2010;19:30-37.

118. Bruce RD, Altice FL, Moody DE, et al. Pharmacokinetic interactions between buprenorphine/naloxone and once-daily lopinavir/ritonavir. J Acquir Immune Defic Syndr. 2010;54:511-514.

119. Bruce RD, Altice FL, Moody DE, et al. Pharmacokinetic interactions between buprenorphine/naloxone and tipranavir/ritonavir in HIVnegative subjects chronically receiving buprenorphine/naloxone. Drug Alcohol Depend. 2009;105:234-239.

120. Gruber VA, Rainey PM, Moody DE, et al. Interactions between buprenorphine and the protease inhibitors darunavir-ritonavir and fosamprenavir-ritonavir. Clin Infect Dis. 2012;54:414- 423.

121. Douglas Bruce R, Moody DE, Chodkowski D, et al. Pharmacokinetic interactions between buprenorphine/naloxone and raltegravir in subjects receiving chronic buprenorphine/naloxone treatment. Am J Drug Alcohol Abuse. 2013;39:80-85.

122. Luo X, Trevejo J, van Heeswijk RP, Smith F, Garg V. Effect of telaprevir on the pharmacokinetics of buprenorphine in volunteers on stable buprenorphine/naloxone maintenance therapy. Antimicrob Agents Chemother. 2012;56:3641-3647.

123. Coller JK, Michalakas JR, James HM, etal. Inhibition of CYP2D6-mediated tramadol O-demethylation in methadone but not buprenorphine maintenance patients. Br J Clin Pharmacol. 2012;74:835-841.

124. McCance-Katz EF, Moody DE, Prathikanti S, Friedland G, Rainey PM. Rifampin, but not rifabutin, may produce opiate withdrawal in buprenorphine-maintained patients. Drug Alcohol Depend. 2011;118: 326-334.

125. Alhaddad H, Cisternino S, Decleves X, et al. Respiratory toxicity of buprenorphine results from the blockage of P-glycoprotein-mediated efflux of norbuprenorphine at the blood-brain barrier in mice. Crit Care Med. 2012;40:3215-3223.

126. Lintzeris N, Nielsen S. Benzodiazepines, methadone and buprenorphine: interactions and clinical management. Am J Addict. 2010;19: 59-72.

127. Boyd J, Randell T, Luurila H, Kuisma M. Serious overdoses involving buprenorphine in Helsinki. Acta Anaesthesiol Scand. 2003;47: 1031-1033. 
128. Kintz P. A new series of 13 buprenorphine-related deaths. Clin Biochem. 2002;35:513-516.

129. Häkkinen M, Launiainen T, Vuori E, Ojanperä I. Benzodiazepines and alcohol are associated with cases of fatal buprenorphine poisoning. Eur J Clin Pharmacol. 2012;68:301-309.

130. Lintzeris N, Mitchell TB, Bond AJ, Nestor L, Strang J. Pharmacodynamics of diazepam co-administered with methadone or buprenorphine under high dose conditions in opioid dependent patients. Drug Alcohol Depend. 2007;91:187-194.

131. Cohier C, Chevillard L, Risede P, Roussel O, Megarbane B. Respiratory effects of buprenorphine/naloxone alone and in combination with diazepam in naive and tolerant rats. Toxicol Lett. 2014;228:75-84.

132. Pirnay S, Megarbane B, Decleves X, et al. Buprenorphine alters desmethylflunitrazepam disposition and flunitrazepam toxicity in rats. Toxicol Sci. 2008;106:64-73.

133. Debruyne D, Quentin T, Poisnel G, Lelong-Boulouard V, Barre L, Coquerel A. Acute and chronic administration of clorazepate modifies the cell surface regulation of mu opioid receptors induced by buprenorphine in specific regions of the rat brain. Brain Res. 2005;1052:222-231.

134. Chang Y, Moody DE. Effect of benzodiazepines on the metabolism of buprenorphine in human liver microsomes. Eur J Clin Pharmacol. 2005;60:875-881.

135. Ferri M, Finlayson AJ, Wang L, Martin PR. Predictive factors for relapse in patients on buprenorphine maintenance. Am J Addict. 2014;23:62-67.

136. Clarke TK, Crist RC, Ang A, et al. Genetic variation in OPRD1 and the response to treatment for opioid dependence with buprenorphine in European-American females. Pharmacogenomics J. 2014;14:303-308.

137. Crist RC, Clarke TK, Ang A, et al. An intronic variant in OPRD1 predicts treatment outcome for opioid dependence in African-Americans. Neuropsychopharmacology. 2013;38:2003-2010.

138. Strain EC, Harrison JA, Bigelow GE. Induction of opioid-dependent individuals onto buprenorphine and buprenorphine/naloxone solublefilms. Clin Pharmacol Ther. 2011;89:443-449.

139. Lintzeris N, Leung SY, Dunlop AJ, et al. A randomised controlled trial of sublingual buprenorphine-naloxone film versus tablets in the management of opioid dependence. Drug Alcohol Depend. 2013;131: $119-126$.

140. Soyka M. Buprenorphine and buprenorphine/naloxone soluble-film for treatment of opioid dependence. Expert Opin Drug Deliv. 2012;9: 1409-1417.

141. Larance B, Lintzeris N, Ali R, et al. The diversion and injection of a buprenorphine-naloxone soluble film formulation. Drug Alcohol Depend. 2014;136:21-27.

142. Centers for Disease Control and Prevention (CDC). Buprenorphine prescribing practices and exposures reported to a poison center - Utah, 2002-2011. MMWR Morb Mortal Wkly Rep. 2012;61:997-1001.

143. Amato L, Minozzi S, Davoli M, Vecchi S. Psychosocial combined with agonist maintenance treatments versus agonist maintenance treatments alone for treatment of opioid dependence. Cochrane Database Syst Rev. 2011;(10):CD004147.

144. Schottenfeld RS, Chawarski MC, Pakes JR, Pantalon MV, Carroll KM, Kosten TR. Methadone versus buprenorphine with contingency management or performance feedback for cocaine and opioid dependence. Am J Psychiatry. 2005;162:340-349.

145. Ling W, Hillhouse M, Ang A, Jenkins J, Fahey J. Comparison of behavioral treatment conditions in buprenorphine maintenance. Addiction. 2013;108:1788-1798.

146. Fiellin DA, Barry DT, Sullivan LE, et al. A randomized trial of cognitive behavioral therapy in primary care-based buprenorphine. $\mathrm{Am} \mathrm{J}$ Med. 2013;126:74. e11-e17.

147. Brooner RK, King VL, Kidorf M, Schmidt CW Jr, Bigelow GE. Psychiatric and substance use comorbidity among treatment-seeking opioid abusers. Arch Gen Psychiatry. 1997;54:71-80.

148. Darke S, Ross J. Polydrug dependence and psychiatric comorbidity among heroin injectors. Drug Alcohol Depend. 1997;48:135-141.
149. Ross J, Teesson M, Darke S, et al. The characteristics of heroin users entering treatment: findings from the Australian treatment outcome study (ATOS). Drug Alcohol Rev. 2005;24:411-418.

150. Rounsaville BJ, Weissman MM, Crits-Christoph K, Wilber C, Kleber H. Diagnosis and symptoms of depression in opiate addicts. Course and relationship to treatment outcome. Arch Gen Psychiatry. 1982;39:151-156.

151. Savant JD, Barry DT, Cutter CJ, et al. Prevalence of mood and substance use disorders among patients seeking primary care office-based buprenorphine/naloxone treatment. Drug Alcohol Depend. 2013;127: 243-247.

152. Schäfer I, Fischer M, Reimer J, Karow A, Haasen C. Significance of psychiatric comorbidity for the outcome of maintenance treatment a review of the literature. Ment Health Subst Use. 2011;4:62-71.

153. Strain EC. Assessment and treatment of comorbid psychiatric disorders in opioid-dependent patients. Clin J Pain. 2002;18:S14-S27.

154. Merikangas KR, Mehta RL, Molnar BE, et al. Comorbidity of substance use disorders with mood and anxiety disorders: results of the International Consortium in Psychiatric Epidemiology. Addict Behav. 1998;23:893-907.

155. Merikangas KR, Zhang H, Avenevoli S, Acharyya S, NeuenschwanderM, Angst J. Longitudinal trajectories of depression and anxiety in a prospective community study: the Zurich Cohort Study. Arch Gen Psychiatry. 2003;60:993-1000.

156. Moggi F. [Etiological models on the relationship of mental disorders and substance use disorders]. Suchtmed. 2013;15:327-333. German.

157. Soyka M. [Affective and anxiety disorders and drug addiction]. Suchtmed. 2013;15:341-348. German.

158. Cacciola JS, Alterman AI, Rutherford MJ, McKay JR, Mulvaney FD. The relationship of psychiatric comorbidity to treatment outcomes in methadone maintained patients. Drug Alcohol Depend. 2001;61: 271-280

159. Darke S, Mills K, Teesson M, Ross J, Williamson A, Havard A. Patterns of major depression and drug-related problems amongst heroin users across 36 months. Psychiatry Res. 2009;166:7-14.

160. Pani PP, Maremmani I, Pacini M, Lamanna F, Maremmani AG, Dell'osso L. Effect of psychiatric severity on the outcome of methadone maintenance treatment. Eur Addict Res. 2011;17:80-89.

161. Stein MD, Solomon DA, Herman DS, et al. Pharmacotherapy plus psychotherapy for treatment of depression in active injection drug users. Arch Gen Psychiatry. 2004;61:152-159.

162. Torrens M, Martínez-Sanvisens D, Martínez-Riera R, Bulbena A, Szerman N, Ruiz P. Dual diagnosis: focusing on depression and recommendations for treatment of opioid dependence. Addict Disord Treat. 2011;10:50-59.

163. Wee S, Koob GF. The role of the dynorphin-kappa opioid system in the reinforcing effects of drugs of abuse. Psychopharmacology (Berl). 2010;210:121-135.

164. Todtenkopf MS, Marcus JF, Portoghese PS, Carlezon WA Jr. Effects of kappa-opioid receptor ligands on intracranial self-stimulation in rats. Psychopharmacology (Berl). 2004;172:463-470.

165. Rothman RB, Gorelick DA, Heishman SJ, et al. An open-label study of a functional opioid kappa antagonist in the treatment of opioid dependence. J Subst Abuse Treat. 2000;18:277-281.

166. Bodkin JA, Zornberg GL, Lukas SE, Cole JO. Buprenorphine treatment of refractory depression. J Clin Psychopharmacol. 1995;15:49-57.

167. Emrich HM, Vogt P, Herz A, Kissling W. Antidepressant effects of buprenorphine. Lancet. 1982;2:709.

168. Gerra G, Leonardi C, D'Amore A, et al. Buprenorphine treatment outcome in dually diagnosed heroin dependent patients: a retrospective study. Prog Neuropsychopharmacol Biol Psychiatry. 2006;30:265-272.

169. Schmauss C, Yassouridis A, Emrich HM. Antipsychotic effect of buprenorphine in schizophrenia. Am J Psychiatry. 1987;144:1340-1342.

170. Gerra G, Di Petta G, D'Amore A, et al. Combination of olanzapine with opioid-agonists in the treatment of heroin-addicted patients affected by comorbid schizophrenia spectrum disorders. Clin Neuropharmacol. 2007;30:127-135. 


\section{Publish your work in this journal}

Substance Abuse and Rehabilitation is an international, peer-reviewed, open access journal publishing original research, case reports, editorials, reviews and commentaries on all areas of addiction and substance abuse and options for treatment and rehabilitation. The manuscript management system is completely online and includes a very quick and fair peer-review system. Visit http://www.dovepress.com/testimonials.php to read real quotes from published authors. 